Proceedings

\title{
Deer as a Natural Disturbance that Supports Landscape and Herbaceous Plant Diversity ${ }^{\dagger}$
}

\author{
Brice Hanberry *, Edward K. Faison
}

* Correspondence: bhanberry@fs.fed.us

+ Presented at the 1st International Electronic Conference on Biological Diversity, Ecology and Evolution, 15-31 March 2021; Available online: https://bdee2021.sciforum.net/.

\begin{abstract}
Natural disturbances are critical ecosystem processes, with both ecological benefits and detriments. Herbivory by deer and other large wild herbivores often is considered a forest health problem, rather than a natural disturbance that results in a broad range of ecological outcomes including many important advantages. Here, we present that deer may be considered a natural disturbance helpful in controlling increased tree and shrub densities during the past century and thereby favoring a diversity of habitats and herbaceous plants. Ecological disadvantages of large herbivores include additional pressure on already declining herbaceous plant species and an increase in some invasive plant species via selective herbivory. We also discuss socioeconomic costs and benefits because society determines whether a species is a problem. Large herbivores are natural disturbances that have been removing plant biomass and altering landscape and vegetation structure for millions of years; similar to other disturbances, deer 'regimes' vary in severity. From a perspective of historical ecology rather than current baselines, deer as a disturbance provide many ecological benefits while socioeconomic effects range from troublesome to enjoyable for society.
\end{abstract}

Keywords: fire; forest health; herbivory; open forests
6

Citation: Brice Hanberry *, Edward K. Faison. Deer as a natural disturbance that supports landscape and herbaceous plant diversity. Proceedings 2021, 68, $\mathrm{x}$.

https://doi.org/10.3390/xxxxx

Publisher's Note: MDPI stays neutral with regard to jurisdictional claims in published maps and institutional affiliations.

Copyright: (c) 2021 by the authors. Submitted for possible open access publication under the terms and conditions of the Creative Commons Attribution (CC BY) license (http://creativecommons.org/licenses /by/4.0/). 